\title{
Effect of Topical Application of Nigella Sativa Oil and Oral Acetaminophen on Pain in Elderly with Knee Osteoarthritis: A Crossover Clinical Trial
}

\author{
Akram Kooshki ${ }^{1}$, Reza Forouzan ${ }^{2}$, Mohammad Hassan Rakhshani $^{3}$, Maryam Mohammadi ${ }^{4}$
}

${ }^{1}$ Ph.D. of Nutrition, Associate Professor, Department of Nutrition \& Biochemistry, Faculty member of Medicine school, Sabzevar University of Medical Sciences, Sabzevar, Iran

${ }^{2}$ MD, Management of Treatment, Sabzevar University of Medical Sciences, Sabzevar, Iran

${ }^{3}$ Ph.D. OF Biostatistics, Assistant Professor, Department of Biostatics, Faculty member of Health School, Sabzevar University of Medical Sciences, Sabzevar, Iran

${ }^{4}$ Ph.D. of Health Education, Assistant Professor, Department of Public Health, Faculty Member of Health School, Shahid Beheshti University of Medical Sciences, Tehran, Iran

\section{Type of article: Original}

\begin{abstract}
Background: Limited evidence supports Nigella sativa's role as an effective complementary and alternative medicine and the anti-inflammatory effects of Nigella sativa on patients with allergic rhinitis.

Objective: The aim of this study was to investigate the effect of topical application of Nigella sativa oil and oral acetaminophen on pain in the elderly with knee osteoarthritis residing in a parents' home in Sabzevar.

Methods: This study is done as a crossover clinical trial. After obtaining written consent of elderly patients with osteoarthritis of the knee, they were randomly divided into two groups. In step 1, in group 1, 1 cc of Nigella sativa oil was applied on the knee joint every 8 hours for 3 weeks; for the second group, every 8 hours for 3 weeks, patients were given 1 tablet of $325 \mathrm{mg}$ acetaminophen. After a period of 1 month without medication to wash out each group, in step 2, each treatment group received the drug interaction in the same way as above. Pain was determined using a visual scale (VAS) before and after the first and second stages. Treatment response was defined as a decrease in pain scores over 1.5. Data analysis was performed with an R software mixed model.

Results: This study was done on 40 elderly patients: $18(45 \%)$ men and $22(55 \%)$ women. Their mean year and weight were $75.66 \pm 8.9$ years and $69.67 \pm 14.33 \mathrm{~kg}$, respectively. Study results showed that topical application of Nigella sativa oil and oral acetaminophen reduced pain in elderly with knee osteoarthritis; after using Nigella sativa oil, the reduction of pain was higher $(\mathrm{p}=0.01)$.

Conclusion: The results of this study showed that topical application of Nigella sativa oil was effective in reducing pain in patients with knee osteoarthritis; therefore, it is recommended as a safe supplement for these elderly.

Trial registration: The trial was registered at TCTR (http://www.clinicaltrials.in.th/) with the ID: TCTR20160125003.

Funding: This study was approved and supported by the Sabzevar University of Medical Sciences.

Keywords: Elderly; Nigella sativa oil; Pain; Osteoarthritis
\end{abstract}

\section{Introduction}

Elderly are considered one of the most vulnerable groups in societies all over the world, and special attention is typically paid to them. In recent years, due to lower mortality rates and improved health and increased life expectancy, the number of elders is more than in any period in history. For every 10 people in the world, a person is over 65 years old. In Iran, also by increasing the proportion, the number of elders has increased, and, according to

\section{Corresponding author:}

Associate Professor Dr. Akram Kooshki, Department of Nutrition \& Biochemistry, Faculty member of Medicine school, Sabzevar University of Medical Sciences, Sabzevar, Iran.

Tel: +98.5144445994, Fax: +98.5144445648, Email: Akooshki.nurt@yahoo.com

Received: January 16, 2016, Accepted: May 24, 2016, Published: November 2016

iThenticate screening: May 24, 2016, English editing: August 20, 2016, Quality control: October 12, 2016

(C) 2016 The Authors. This is an open access article under the terms of the Creative Commons Attribution-NonCommercialNoDerivs License, which permits use and distribution in any medium, provided the original work is properly cited, the use is non-commercial and no modifications or adaptations are made. 
the latest statistics, $7.8 \%$ of the country's population is made up of elder people; due to population growth, it is predicated that the levels during the next decade will reach to $16 \%$ of the total population (1). The prevalence of physical disabilities will increase with increasing the population ageing; thus this inability results from many causes, among them the loss of mobility is of greatest importance (2). Osteoarthritis is of the most common joint disease and disability in most countries of the world $(1,2)$. It has a higher incidence rate before age 50 in men and later in women (2). The knee is one of the most common joints, where almost $10 \%$ of the population has had knee pain over 65 years (3), and about $25 \%$ of people aged 55 years and older have reported a history of knee pain in the past few years. Treatment for osteoarthritis includes medications, surgery, and complementary therapies. However, these therapies are not completely effective. Some studies have shown that the use of nonsteroidal anti-inflammatory drugs (NSAIDS) may increase heart disease and cardiovascular or gastrointestinal disorders $(4,5)$. In a study, it was suggested that nonsteroidal anti-inflammatory drug commonly are prescribed, which will increase the degradation of joint cartilage in osteoarthritis through the inhibition of the synthesis of cartilage matrix (6). Thus many researchers are looking for drugs, while effective, that have fewer adverse side effects, among which herbal drugs may be mentioned. From the earliest times, the therapeutic effects of medicinal plants have been considered. It is a common belief in Islamic countries that Nigella sativa is a general healer to cure diseases but cannot prevent aging and death. The plant, with the scientific name of Nigella sativa, is a member of the Ranunculaceae family: it has white flowers, white or blue with milky grains that become black in contact with air. Nigella sativa has a medical and religious history. It is native to southern Europe and North Africa and Asia and had been used to treat illnesses by ancient Egyptian and Greek doctors and Avicenna (7). Nigella sativa oil is composed of 30\% by weight of p-cymene, which is the most original composition, and $61.48 \%$ of the weight is composed of the volatile oil. Nigella sativa seeds contain fat, vitamins, minerals, proteins, essential amino acids, and carbohydrates (8). Nigella sativa seed is a rich source of essential fatty and unsaturated acids. The main unsaturated fatty acids are linoleic acid and oleic acid. There are also other compounds in seeds, such as phospholipids, carotene, calcium, iron, and potassium (9). Various evidence suggests that, due to the beneficial use of this plant on kidney function, blood pressure regulation system, the ability to detoxify the liver, the respiratory system's ability to dispose of waste, the production of sweat, and textured milk, available evidence indicates that components of Nigella sativa oil and active components, especially $\mathrm{TQ}$, have antioxidant and anti-inflammatory, anti-inflammatory, and analgesic properties that are applied through the suppression of inflammatory mediators such as prostaglandins and thymoquinone (10). Hajhashemi and colleagues noted that Nigella sativa oil has 20 different chemical compositions, among those the semen parameters and thymoquinone are two major components, which are both systemic and topical prescriptions of antiinflammatory and analgesic properties (11). A study that Roghani and colleagues conducted on rats found that oral prescription of Nigella sativa for two months resulted in a significant reduction in pain in the rats (12). According to a mobility disability caused by osteoarthritis among the elderly, a lot of side effects of synthetic drugs and multiple medications by the elderly exist with no certain cure for it; thus the prevalence of musculoskeletal disorders has been reported in older people in Sabzevar City, especially in the knee joint $(13,14)$. This study was to evaluate the topical impact of Nigella sativa oil and oral acetaminophen on knee osteoarthritis in the elderly residing in a parents' nursing home in Sabzevar City of Iran.

\section{Material and Methods}

\subsection{Study setting and participants}

This study was conducted as a clinical trial (crossover) from November 21, 2014, to January 20, 2014. Procedure of the study was justified in elderly patients with osteoarthritis of the knee in elderly residing in a parents' nursing home in Sabzevar City in Iran.

\subsection{Inclusion criteria}

All patients were evaluated before inclusion in this study. Age over 65 years diagnosis of knee osteoarthritis, according to American College Rheumatology diagnostic criteria, included 1) knee pain on most days of the last month; 2) crepitus (joint sound in active motion); 3) morning stiffness less than 30 minutes; and 4) inflation in the examination of the knee bone, respectively (15). Knee osteoarthritis was confirmed by a physician, and the use of radiography, knee pain in the past 24 hours, so that the average linear measure-visual pain (VAS: visual analogue score) is between $4-7 \mathrm{~cm}$, and the lack of inflammatory diseases, metabolic disorders (diabetes), cancer or malignant diseases, symptoms or a history of liver or kidney failure, treatment with oral corticosteroids in the past 4 weeks or injection in the last 6 months, no fever, lack of sensitivity and allergy Nigella sativa oil, not wanting to continue to participate in the study, supplementation with vitamins and minerals or other nutritional supplements, painkillers were the exit standards of the study. 


\subsection{Intervention}

After obtaining written consent for their demographic questionnaire, seniors eligible for the study were randomly divided into two groups. In the first stage, for the first group about $1 \mathrm{ml}$ Nigella sativa oil was applied on the knee joint three times a day every 8 hours for 1 week. The massaging method was done with the entire palm in a way that continued for 5 minutes, massaged in a clockwise direction at the front and sides of the knee joint. It should be noted that the Nigella sativa oil used was owned by Barij-e-Kashan; for all subjects, it was maintained away from sunlight and at ambient temperature. The second group was given $325 \mathrm{mg}$ acetaminophen tablets 3 times a day every 8 hours for 3 weeks. Then a 1-month period without medication to wash out was given to each group, and then each treatment group received the contrary drug in the same way as above. If patients were taking the drug irregularly or because of pain medication or because other treatment methods were used, or for whatever reason, and were not able to continue the treatment and completion of the study, they were excluded from the study.

\subsection{Outcomes}

The pain intensity was determined using the visual analogue linear scale (VAS) before and after the first and second stages of the study. The standard was a 10-inch ruler on which the patient were asked to rate his or her pain intensity from 0 to 10 . Before taking the medication, individuals marked their pain on the ruler. Mild pain distances of 0 to 3 , 4 to 7 moderate pain, and severe pain showed 8-10 (16). Response to treatment was measured for reduction of more than $5.1 \mathrm{~cm}$ on the VAS scale in the pain.

\subsection{Sample size and statistical analysis}

In the sample size required by the consultant statistics with $95 \%$ confidence level and 5\% error and $90 \%$ power, 37 patients were assessed as probable loss by $10 \%$ to $42 \%$. Data analysis was performed with an R software mixed model.

\subsection{Research ethics}

The study protocol was approved by the Ethics Committee of the National Research Center, Cairo, Egypt. All patients were informed thoroughly about the study, and each patient was asked to sign a consent form. Only motivated and cooperative patients, who accepted the periodic recall visits and agreed to sign the consent form, were enrolled.

\section{Results}

Forty-two patients participated in this study (two patients were excluded due to noncooperation). Eighteen (45\%) were male and $22(55 \%)$ were female, with a mean age of $75.66 \pm 8.9$ years and average weight of $69.67 \pm 14.33 \mathrm{~kg}$. Their activity was less than 1 hour a day for being exposed to sunlight 1 to 2 hours per day. R software mixed model showed that mean of pain intensity was $4.23 \pm 0.31$ and $4.76 \pm 0.31$ in the Nigella sativa oil and oral acetaminophen groups, respectively. Also, topical use of Nigella sativa oil and oral acetaminophen reduced knee pain in elder patients $(\mathrm{p}=0.0001)$. The $\mathrm{R}$ software mixed model showed that pain intensity relief was 0.53 higher in Nigella sativa oil compared with oral acetaminophen $(\mathrm{p}=0.01)$.

\section{Discussion}

Nigella sativa (N. Sativa) has a distinct reputation in Eastern medicine, and it is a commonly used ingredient in many recipes in South Asia and elsewhere (17). In this study, the topical use of 1 cc Nigella sativa oil 3 times a day for 3 weeks reduced knee pain compared with oral acetaminophen in elderly patients with knee osteoarthritis with moderate pain. More researches have recognized analgesic, antispasm, and anti-inflammatory effects in in vivo and in vitro studies $(18,19)$. Our results were consistent with the results of Gheita's study, which was performed on 40 women, who received Nigella sativa oil capsules $500 \mathrm{mg}$ twice daily compared with a placebo, he and his colleagues reported that pain was reduced significantly due to improvement of patients (20). Also Tekeoqlu and colleagues conducted a study on mice by measuring TNF- $\alpha$ IL-1 $\beta$, which showed that TQ (Nigella sativa) demonstrated that the substance can significantly suppress arthritis in mice (21). Bashir and colleagues (2010) showed that the ethanol extract of nigella sativa has a significant analgesic effect in albino rats, but the effect on the reduction of sodium diclofenac was less than that, which was not consistent with our research results because, in our study, the effect of Nigella sativa oil was more significant than acetaminophen for pain relief (22). Yet, no study has examined the topical use of Nigella sativa oil on pain; however, Emami Razavi and colleagues conducted a study on 154 patients with knee pain. They treated patients in three groups as involved groups with frankincense oil-sesame oil in the control group, and diclofenac gel for the positive control group for six weeks. Their study confirmed the potential effects of topical administration of frankincense oil in the symptomatic treatment of knee pain (23). Thymoquinone 
is one of four active ingredients in aqueous extracts of Nigella cumin. Thymoquinone is reported to inhibit oxidative stress. One way of decreasing oxidative stress is to induce glutathione. Mohamed et al. tested the impact of thymoquinone $(1 \mathrm{mg} / \mathrm{kg}$, injected in the tail vein) in rats. They reported that thymoquinone may have a role in treatment of multiple sclerosis (24). The anti-inflammatory effect of the N. Sativa was observed, and studies have shown that black cumin reduced the pain. Ghannadi et al. suggest that Nigella sativa has analgesic and antiinflammatory effects due to its polyphenols (25). Naggar and colleagues also stated that Nigella sativa extract has analgesic effect on the CNS (24). Several studies also showed that Nigella sativa inhibits inflammation with reducing the nitric oxide production and inhibiting cytokines interleukin-1 and 6 and the transcription factor $\beta \mathrm{K}$ inflammation. Also, some studies have stated that Nigella sativa reduced the synthesis of MCP-1, TNF- $\alpha$, and IL- $\beta 1$ and inhibited the histone deacetylases Cox-2 as well as demonstrated its anti-inflammatory properties with the induction of histone hyper acetylation. Nigella sativa oil has demonstrated a mild effect on the expression of Cox-1 and PGE-2 in animal models of respiratory allergies (26-28).

\section{Conclusions}

This study showed that topical use of Nigella sativa oil can be more effective in reducing knee pain in elderly patients than acetaminophen, which is typically used as a safe supplement for the elderly. Further investigation is needed to establish the mechanisms involved. It is also recommended that the consumption of Nigella sativa oil be continued for a longer period of time.

\section{Acknowledgments:}

This study was approved and supported by Sabzevar University of Medical Sciences. The authors would like to express appreciation to the subjects for their participation in this study.

\section{Clinical trial registration:}

The trial was registered at Thai Clinical Trials Registry (TCTR, URL: http://www.clinicaltrials.in.th) with the ID: TCTR20160125003.

\section{Funding:}

This study was approved and supported by Sabzevar University of Medical Sciences.

\section{Conflict of Interest:}

There is no conflict of interest to be declared.

Authors' contributions:

All authors contributed to this project and article equally. All authors read and approved the final manuscript.

\section{References:}

1) Ghasemi S, Sharifi F, Maghsoudinia Sh, Taimouri F. The effect of nutrition health education on Tehran's Kahrizak nursing staff in nutritional health promotion of the elderly in the nursing home. Iran J Aging. 2006; 1(1): 34-45.

2) Novdehi Moghaddam A, Ehssani far F. Assessment of mobility disorders in elderly referred to Behzisti rehabilitation center in Tehran. Iranian J Aging. 2006; 1(2): 125-31.

3) Felson DT. Clinical practice. Osteoarthritis of the knee. N Engl J Med. 2006; 354(8): 841-8. doi: 10.1056/NEJMcp051726. PMID: 16495396.

4) Mamdani M. The changing landscape for COX-2 inhibitors-a summary of recent events. Health CQ. 2005; 8(2): 24-6. PMID: 15828561.

5) Silverstein FE, Fach G, Goldstein JL, Simon LS, Pincus T, Whelton A, et al. Gastrointestinal toxicity with celecoxib vs nonsteroidal anti-inflammatory drugs for osteoarthritis and rheumatoid arthritis: the class study: a randomized controlled trial. Celecoxib Long-term Arthritis Safety Study. JAMA. 2000; 284(10): 1247-55. doi: 10.1001/jama.284.10.1247. PMID: 10979111.

6) Dingle JT. The effects of NSAID on the matrix of human articular cartilages. Zeitschrift für Rheumatologic. Z Rheumatol. 1999; 58(3): 125-9. PMID: 10441838.

7) Salehi surmaghi MH. Nigella Sativa In Herbal Medicine and Herbal Therapy. Donyay Taghziah press. 2008: 216-9. 
8) Geng D, Zhang S, Lan J. Analysis on chemical components of volatile oil and determination of thymoquinone from seed of Nigella glandulifera. Zhongguo Zhong Yao Za Zhi. 2009; 34(22): $2887-90$. PMID: 20209952.

9) Ali BH, Blunden G. Pharmacological and toxicological properties of Nigella sativa. Phytother Res. 2003; 17(4): 299-305. doi: 10.1002/ptr.1309. PMID: 12722128.

10) Valizadeh N, Zakeri HR, Amin asnafi G, Shafiei A, Sarkheil P, Heshmat R, et al. Impact of Black seed (Nigella sativa) extract on bone turnover markers in postmenopausal women with osteoporosis. DARU. 2009; 17(1): 20-5.

11) Hajhashemi V, Ghannadi A, Jafarabadi H. Black cumin seed essential oil, as a potent analgesic and antiinflammatory drug. Phytother Res. 2004; 18(3): 195-9. doi: 10.1002/ptr.1390. PMID: 15103664.

12) Roughani M, Balouchnejad Mojarrad T, Sajadi M, Kavandi A, Kargar Sharif F. Long-term analgesic effect of oral administration of Nigella sativa on diabetic rats. J Sadoghi Yazd Uni Med scien. 2006; 14(2): 38-43.

13) Razavi SM, Bashtny A, Zarghan SH, Tabarraie Y. Prevalence and factors associated with musculoskeletal disorders in agriculture city of Sabzevar. Med Sab J. 2014; 20(20): 766-72.

14) Khosroabadi AA, Razavi SM, Fallahi M, Akaberi A. prevalence of musculoskeletal disorders in health care workers - Sabzevar University of Medical Sciences. Med Sab J. 2007; 17(3): 218-23.

15) Bijlsma JW, Berenbaum F, Lafeber FP. Osteoarthritis: An update with relevance for Clinical practice. Lancet. 2011; 377(9783): 2115-26. doi: 10.1016/S0140-6736(11)60243-2. PMID: 21684382.

16) Wewers ME, Lowe NK. A critical review of visual analogue scales in the measurement of clinical phenomena. Res Nurs Health. 1990; 13(4): 227-36. doi: 10.1002/nur.4770130405. PMID: 2197679.

17) Rehmani Gh, And L, Rohra DK, Rohra DK. Targeting apoptosis with compounds from commonly-used medicinal plants: a possible aid in the fight against cancer. Med Hypothesis Res. 2006; 3(1): 643-50.

18) Hajhashemi V, Ghannadi A, Jafarabadi H. Black cumin seed essential oil, as a potent analgesic and anti inflammatory drug. Phytother Res. 2004; 18(3): 195-9. doi: 10.1002/ptr.1390. PMID: 15103664.

19) Ramadan MF. Nutritional value, functional properties and nutraceutical applications of black cumin (Nigella sativa L): an overview. Intern J Food Scien Technol. 2007; 42(10): 1208-18. doi: 10.1111/j.13652621.2006.01417.x.

20) Gheita TA, Kenawy SA. Effectiveness of Nigella sativa Oil in the Management of Rheumatoid Arthritis Patients: A Placebo Controlled Study. Phytother Res. 2012; 26(8): 1246-8. doi: 10.1002/ptr.3679. PMID: 22162258.

21) Tekeoglu I, Dogan A, Ediz L, Budancamanak M, Demirel A. Effects of thymoquinone (volatile oil of black cumin) on rheumatoid arthritis in rat models. Phytother Res. 2007; 21(9): 895-7. doi: 10.1002/ptr.2143. PMID: 17562570.

22) Bashir MU, Qureshi HJ. Analgesic effect of Nigella sativa seeds extract on experimentally induced pain in albino mice. J Coll Physicians Surg Pak. 2010; 20(7): 464-7. doi: 04.2010/JCPSP.464467. PMID: 20642947.

23) Razavi Emami SZ, Karimi M, Kamalnejad M. Assessment of effect of oil on knee pain in patients with knee osteoarthritis. J Islam Iran Tradit Med. 2012; 3(2): 183-90.

24) Mohamed A, Shoker A, Bendjelloul F, Mare A, Alzrigh M, Benghuzzi H, et al. Improvement of experimental allergic encephalomyelitis (EAE) by thymoquinone; an oxidative stress inhibitor. Bio Med Scien Instrum. 2002; 39: 440-5. PMID: 12724933.

25) Ghannadi A, Hajhashemi V, Jafarabadi H. An investigation of the analgesic and anti-inflammatory effects of Nigella sativa seed polyphenols. J Med Food. 2005; 8(4): 488-93. doi: 10.1089/jmf.2005.8.488. PMID: 16379560.

26) Al-Naggar TB, Gómez-Serranillos MP, Carretero ME, Villar AM. Neuropharmacological activity of Nigella sativa L. extracts. J Ethnopharmacol. 2003; 88(1): 63-8. doi: 10.1016/S0378-8741(03)00157-0. PMID: 12902052.

27) Ahmad A, Husain A, Mujeeb M, Khan SA, Najmi AK, Siddique NA, et al. A review on therapeutic of Nigella Sativa. Amiracle herb. Asian Pacific J Tropic Biomed. 2013; 3(5): 337-52. doi: 10.1016/S22211691(13)60075-1. PMID: 23646296, PMCID: PMC3642442.

28) Darakhshan S, Bidmeshki Pour A, Hosseinzadeh Colagar A, Sisakhtnezhad S. Thymoquinone and its therapeutic potentials. Pharmacol Res. 2015; 95-96: 138-58. doi: 10.1016/j.phrs.2015.03.011. PMID: 25829334. 